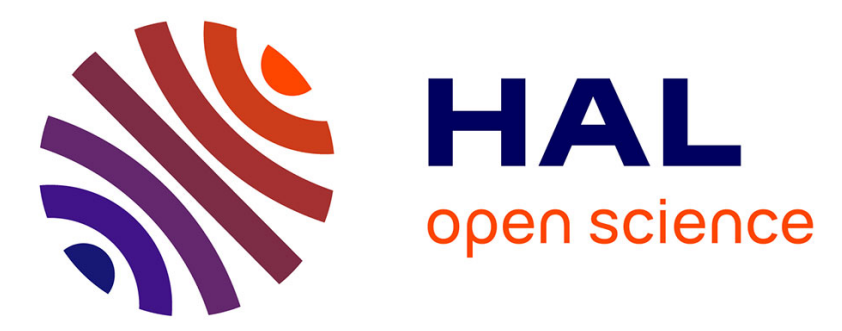

\title{
Chronic toxicity of double-walled carbon nanotubes to three marine organisms: influence of different dispersion methods
}

Kevin Wh Kwok, Kenneth My Leung, Emmanuel Flahaut, Jinping Cheng, Shuk Han Cheng

\section{To cite this version:}

Kevin Wh Kwok, Kenneth My Leung, Emmanuel Flahaut, Jinping Cheng, Shuk Han Cheng. Chronic toxicity of double-walled carbon nanotubes to three marine organisms: influence of different dispersion methods. Nanomedicine, 2010, vol. 5 ( $\mathrm{n}^{\circ}$ 6), pp. 951-961. 10.2217/nnm.10.59 . hal-01562933

\section{HAL Id: hal-01562933 \\ https://hal.science/hal-01562933}

Submitted on 17 Jul 2017

HAL is a multi-disciplinary open access archive for the deposit and dissemination of scientific research documents, whether they are published or not. The documents may come from teaching and research institutions in France or abroad, or from public or private research centers.
L'archive ouverte pluridisciplinaire HAL, est destinée au dépôt et à la diffusion de documents scientifiques de niveau recherche, publiés ou non, émanant des établissements d'enseignement et de recherche français ou étrangers, des laboratoires publics ou privés. 


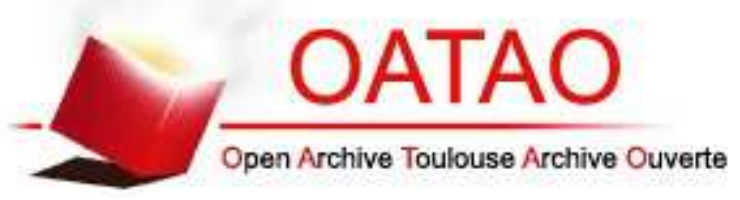

\section{Open Archive TOULOUSE Archive Ouverte (OATAO)}

OATAO is an open access repository that collects the work of Toulouse researchers and makes it freely available over the web where possible.

This is an author-deposited version published in : http://oatao.univ-toulouse.fr/ Eprints ID : 8679

To link to this article : DOI: $10.2217 / \mathrm{nnm} .10 .59$

URL : http://dx.doi.org/10.2217/nnm.10.59

To cite this version : Kwok, Kevin WH and Leung, Kenneth MY and Flahaut, Emmanuel and Cheng, Jinping and Cheng, Shuk Han Chronic toxicity of double-walled carbon nanotubes to three marine organisms: influence of different dispersion methods. (2010) Nanomedicine, vol. 5 ( $\mathrm{n}^{\circ}$ 6). pp. 951-961. ISSN 1743-5889

Any correspondence concerning this service should be sent to the repository administrator: staff-oatao@ listes-diff.inp-toulouse.fr 


\title{
Chronic toxicity of double-walled carbon nanotubes to three marine organisms: influence of different dispersion methods
}

\begin{abstract}
Aim: Double-walled carbon nanotubes (DWNTs) are found in a variety of consumer products, but there are no ecotoxicity data of DWNTs into marine organisms. Materials \& methods: Chronic toxicity of DWNTs was investigated with the diatom Thalassiosira pseudonana, copepod Tigriopus japonicus and medaka Oryzias melastigma. DWNTs were dispersed using sonication (so-DWNTs) and stirring (st-DWNTs) for comparison. Results: The median aggregation size $\left(0.89 \mu \mathrm{m}^{2}\right)$ of so-DWNTs was smaller than that of st-DWNTs $\left(21.8 \mu \mathrm{m}^{2}\right)$. Exposure to DWNTs led to growth inhibition of T. pseudonana with $\mathrm{EC}_{50} \mathrm{~s}$ of 1.86 and $22.7 \mathrm{mg} / \mathrm{l}$ for so- and st-DWNTs, respectively. Population growth of $T$. japonicus was reduced to $0.1 \mathrm{mg} / \mathrm{l}$ for so-DWNTs and $10 \mathrm{mg} / \mathrm{l}$ for st-DWNTs. Growth inhibition in 0 . melastigma was observed at $10 \mathrm{mg} / \mathrm{l}$ for so-DWNTs but not for st-DWNTs. Conclusion: Given that so-DWNTs are consistently significantly more toxic than st-DWNTs, dispersion method and size of aggregations should be considered in DWNT toxicity testing.
\end{abstract}

\section{KEYWORDS: ecotoxicity growth inhibition marine environment nanomaterials} population effect

Following the recent proliferation of nanotechnology, a diverse array of engineered nanomaterials has been produced over the last decade. Engineered nanomaterials are commonly defined as materials with at least one dimension of $100 \mathrm{~nm}$ or less [1]. Such materials typically possess nanostructure-dependent properties (e.g., special chemical, mechanical, electrical, optical, magnetic and/or biological attributes), which make them desirable for commercial or medical applications [1]. Carbon-based nanomaterials and nanoscale metal oxides are two major types of engineered nanomaterials suitable for diverse purposes.

Carbon nanotubes (CNTs) are one of the most promising carbon-based nanomaterials. There are many variations in the structure of CNTs, such as single-walled and multiwalled CNTs of different length and diameter. CNTs have superior electrical conductivity, thermal conductivity and mechanical strength over conventional materials, making them desirable for many commercial products [2]. Potential applications of CNTs include electronic devices, composite materials, hydrogen storage and field emission devices [2]. Recently, double-walled CNTs (DWNTs) are attracting increasing attention because they possess combined advantageous properties of single-walled CNTs (SWNTs) and multiwalled CNTs (MWNTs) [3]. For example, DWNTs offer excellent field emission properties because they have both the low threshold voltage for electron emission as SWNTs and high emission stability similar to MWNTs [4]. Generally, the outer wall of DWNTs protects the inner one, thus maintaining the main mechanical properties even in case of covalent fictionalization. Hence, DWNTs have a morphology very similar to SWNTs (in terms of length and diameter), with improved mechanical properties.

The application of CNTs is vast and is expanding. The annual number of CNT-related patents filed between 1997 and 2001 increased from approximately 2500 to approximately 21,000 [2]. The annual number of DWNTrelated patents filed also increased from eight to approximately 250 between 2000 to 2008 [101]. A total of 65 tons of CNTs and nanofibers was produced in 2004 and their production is projected to increase by $60 \%$ per year [102]. Furthermore, CNTs will become more affordable as their prices are anticipated to decrease by factors of 10-100 [102]. The CNT market in 2007 was estimated to be worth approximately US $\$ 79$ million, with a compound annual growth rate of $74 \%$ [103]. Applications of CNTs are already beginning to be realized in commercial consumer products, and are already in sports equipment, electronics and as additives to plastics [104].

With the increasing production and utilization of these unique nanomaterials, CNTs and their by-products are likely to enter aquatic environments. Possible release pathways include industrial discharge, landfill leachate, accidental spill or marine dumping of contaminated mud. Besides such unintentional releases, intentional

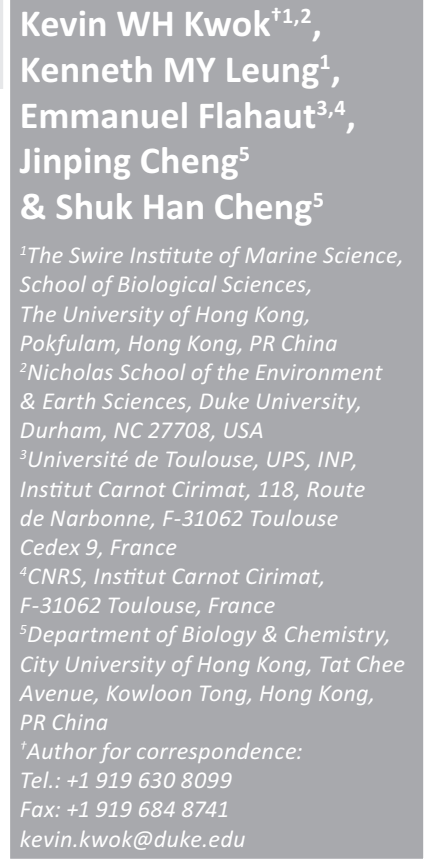




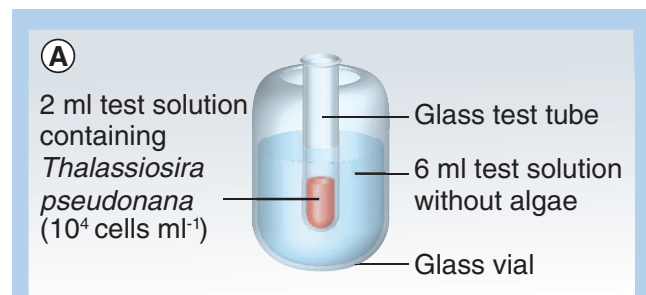

(B)

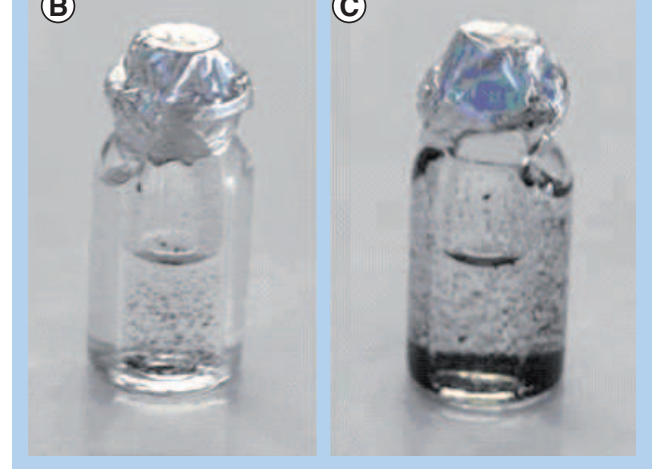

Figure 1. Experimental set-up for algal growth inhibition test. (A) An illustrated diagram of the set-up. (B) A set-up testing the toxicity of double-walled carbon nanotube and (C) a set-up testing the light-blocking effect of double-walled carbon nanotube.

release for environmental remediation [5] and wastewater treatment [6] may also introduce these nanomaterials into the environment. Therefore it is important to gain an understanding of their potential risks of exposure in ecosystems. In addition, current regulation on disposal or discharge of engineered nanomaterials is unclear. The lack of understanding and regulation regarding the potential impacts of nanomaterials to the environment has been a key concern under scrutiny by environmental scientists [7].

Properties of nanomaterials are, however, different from the bulk properties of the constituent chemicals [8] and therefore require separate investigation for their ecotoxicities [1]. Most of the recent literature on the toxicity of CNTs has focused on in vitro and mammalian models, and these studies have confirmed that CNTs can have toxic effects by inducing oxidative stress and respiratory toxicity [1,9]. Ecotoxicity of CNTs has also been partially revealed in a few studies on fish and invertebrates. For example, the rainbow trout Oncorhynchus mykiss exposed to $0.1 \mathrm{mg} / \mathrm{l} \mathrm{SWNTs}$ displayed increased ventilation rate and altered behavior [10]. Hatching of zebrafish embryos was significantly delayed in test solution with SWNTs at $120 \mathrm{mg} / \mathrm{l}[8]$. The copepod Amphiascus tenuiremis exposed to $10 \mathrm{mg} / \mathrm{l}$ SWNTs exhibited significant reduction in lifecycle survivorship, fertilization successes and molting success [11]. In addition, previous mammalian studies demonstrated many adverse effects of CNTs but such toxic effects generally require a long period to develop $[12,13]$.

It is very common for nanomaterials to agglomerate into large aggregates due to strong van der Waals forces, especially for CNTs [14]. From the view point of ecotoxicology, it is more important to study the environmentally realistic form of nanomaterial aggregates [15]. Typically, solvents/ surfactants or sonication are used to disperse $\mathrm{CNTs}$ in aqueous suspensions for the majority of previous toxicity studies. Nevertheless, these two dispersion methods are environmentally unrealistic. Using solvents/surfactants have an additional disadvantage, as the solvent itself can cause significant toxicity under some circumstances [10]. Stirring may be a more environmentally realistic option to disperse CNTs in aqueous solution, despite not being able to disperse CNTs as well as the previous two methods [16]. Different methods of dispersion may result in different degrees or kinds of agglomeration of CNTs. For example, it has been shown that CNTs of different aggregation sizes can cause different toxicities to mammalian cell lines $[17,18]$. Nonetheless, there is no similar in vivo study to uncover the influence of different dispersion methods on the CNT toxicity to marine organisms.

The objective of this study was to evaluate the ecotoxicity of DWNTs in a marine environment. Their toxicities were tested with three common saltwater model species: the diatom Thalassiosira pseudonana, the copepod Tigriopus japonicus and the medaka fish Oryzias melastigma. To understand the potential effect of dispersion method on DWNT toxicity, toxicities of DWNTs dispersed by stirring and sonication were compared.

\section{Methods \\ Nanomaterial suspension preparation \& characterization}

Double-walled carbon nanotubes used in this study were produced by catalytic chemical vapor deposition method, and the synthesis and characterization was published in an earlier study [3]. In brief, the batch contained about $80 \%$ DWNTs and $20 \%$ SWNT. The inner and outer diameters of DWNTs were approximately 0.7 to $2.1 \mathrm{~nm}$, respectively [3]. The DWNT sample contains ca. $90 \%$ elemental carbon with traces of elemental cobalt (ca. 3.3 wt.\%) and molybdenum (ca. 1.1 wt.\%), as well as oxygen [3]. Cobalt contaminants were present but were in the form of carbonencapsulated nanoparticles [3]. The carbon-encapsulated metal nanoparticles are tightly protected 
from the outside environment [19] and no leak of metal is expected in the experimental conditions used in this work.

Autoclaved, filtered artificial seawater $(30 \pm 0.5 \% ; \mathrm{pH} 7.9-8.0)$ was used for all the experiments and was prepared by dissolving the appropriate amount of artificial sea salt in distilled water followed by filtration (sea salt: Tropic Marine, Germany; filter: glass microfiber filter GF/C $47 \mathrm{~mm}$ circle, Whatman, UK). Stock solutions were prepared by dispersing $0.0100 \mathrm{~g}$ of DWNTs, determined gravimetrically (fivedigit electronic balance, Sartorius, Germany) in $100 \mathrm{ml}$ of artificial seawater. DWNTs were dispersed in artificial seawater using either sonication (Branson 5200 ultrasonic bath) for $2 \mathrm{~h}$ (soDWNT) or continuous stirring with a magnetic stirrer ( $200 \mathrm{rpm})$ for 2 weeks (st-DWNT). All the suspensions were examined under transmission electron microscopy (TEM; FEI CM208, Eindhoven, The Netherlands) at $80 \mathrm{kV}$ to obtain the distribution of their aggregation size.

\section{Experimental organisms}

Diatom (T. pseudonana), culture was maintained in autoclaved $\mathrm{f} / 2$-Si medium under $25 \pm 1^{\circ} \mathrm{C}$, $30 \pm 0.5 \%$, pH 7.8-8.1 and a $16: 8 \mathrm{~h}$ photoperiod. Harpacticoid copepods (T. japonicus), were maintained under identical environmental conditions as those set for T. pseudonana and were fed with the diatom Skeletonema costatum. The medaka fish (O. melastigma) were maintained at $25 \pm 2^{\circ} \mathrm{C}, 30 \pm 2 \%$, pH 7.8-8.1 and a 16:8 h photoperiod, and fed with commercial fish feed (Kyorin, Japan) and newly hatched artemia larvae $(<24 \mathrm{~h}$ old $)$.

\section{- 96-h algal growth inhibition test}

As DWNTs are opaque, growth inhibition may be an effect of light blockage caused by the materials instead of direct toxicity. In order to differentiate between the two effects, the experimental set-up was specially designed as shown in Figure 1A. Cell concentration of T. pseudonana culture at exponential growth phase $(96 \mathrm{~h}$ old $)$ was determined using a hemocytometer (Neubauer Improved, Precolor HGB, Germany). An appropriate amount of diatom culture was added to each of the $3.5 \mathrm{ml}$ autoclaved test glass tubes with $2 \mathrm{ml}$ autoclaved f/2-Si medium to obtain an initial algal concentration of $10^{4}$ cells $/ \mathrm{ml}$. Different concentrations of DWNTs $(0.1,1,10$, 50 and $100 \mathrm{mg} / \mathrm{l}$ ) were added to the test tubes. The algal solution was placed in a $3.5 \mathrm{ml}$ glass test tube and this test tube was placed inside a small glass vial containing $6 \mathrm{ml}$ test solution.
When the toxicity of DWNTs was tested, the nanomaterials were mixed with the algae and only water was added to the outside glass vial (Figure 1B). When the light-blocking effect was being investigated, the materials were added to the solution of the outside glass vial (Figure 1C). In order to understand whether this additional glass vial itself would affect the growth of the algae, an additional water control without the glass vial was included. There were four replicates
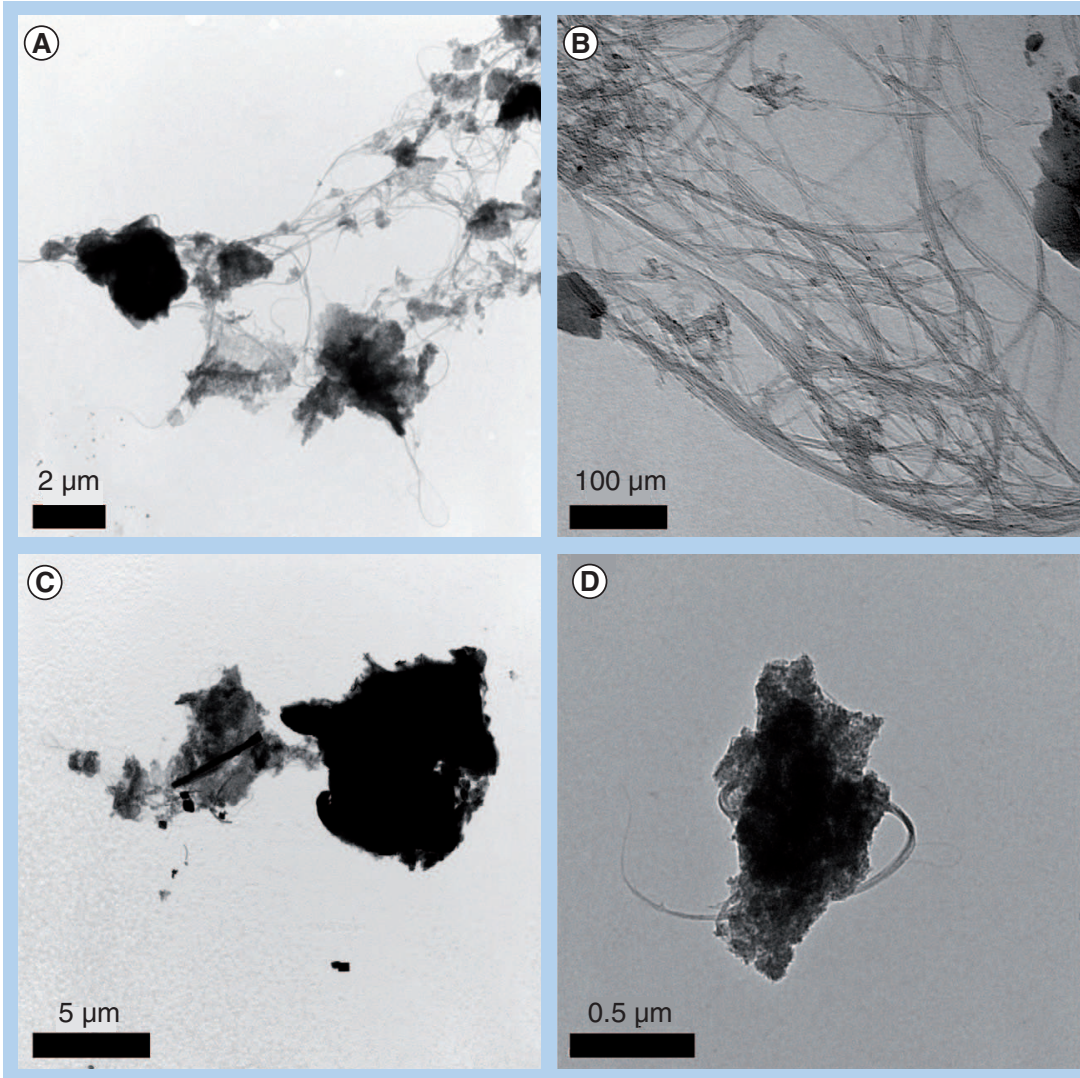

(D)

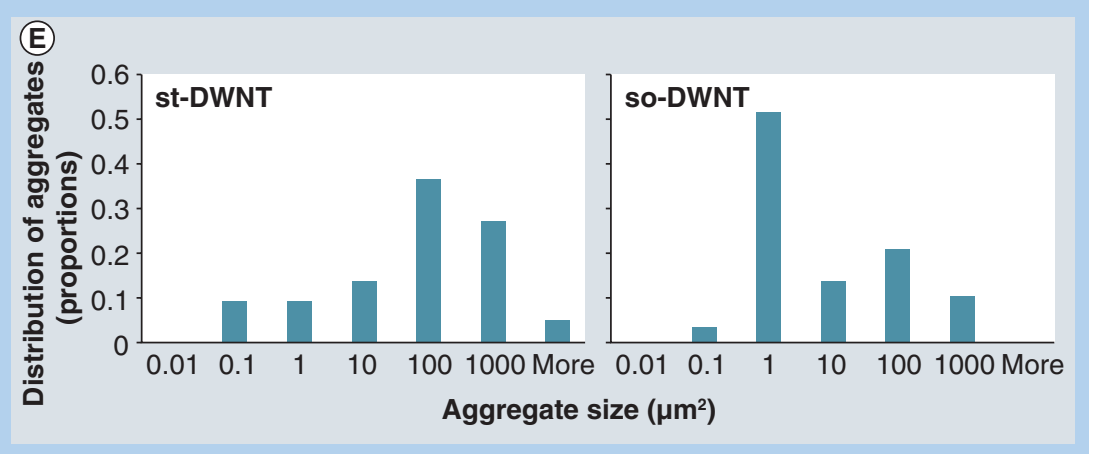

Figure 2. Transmission electron microscope photos and size distributions of both sonicated and stirred double-walled carbon nanotubes aggregates. Transmission electron microscope photos of so-DWNT aggregates under (A) low magnification and (B) high magnification; and st-DWNT aggregates under (C) low magnification and (D) high magnification. From the transmission electron microscope analysis, aggregation size distributions of both so- and st-DWNTs are determined and shown in (E).

so-DWNT: Sonicated double-walled carbon nanotube; st-DWNT: Stirred double-walled carbon nanotube. 


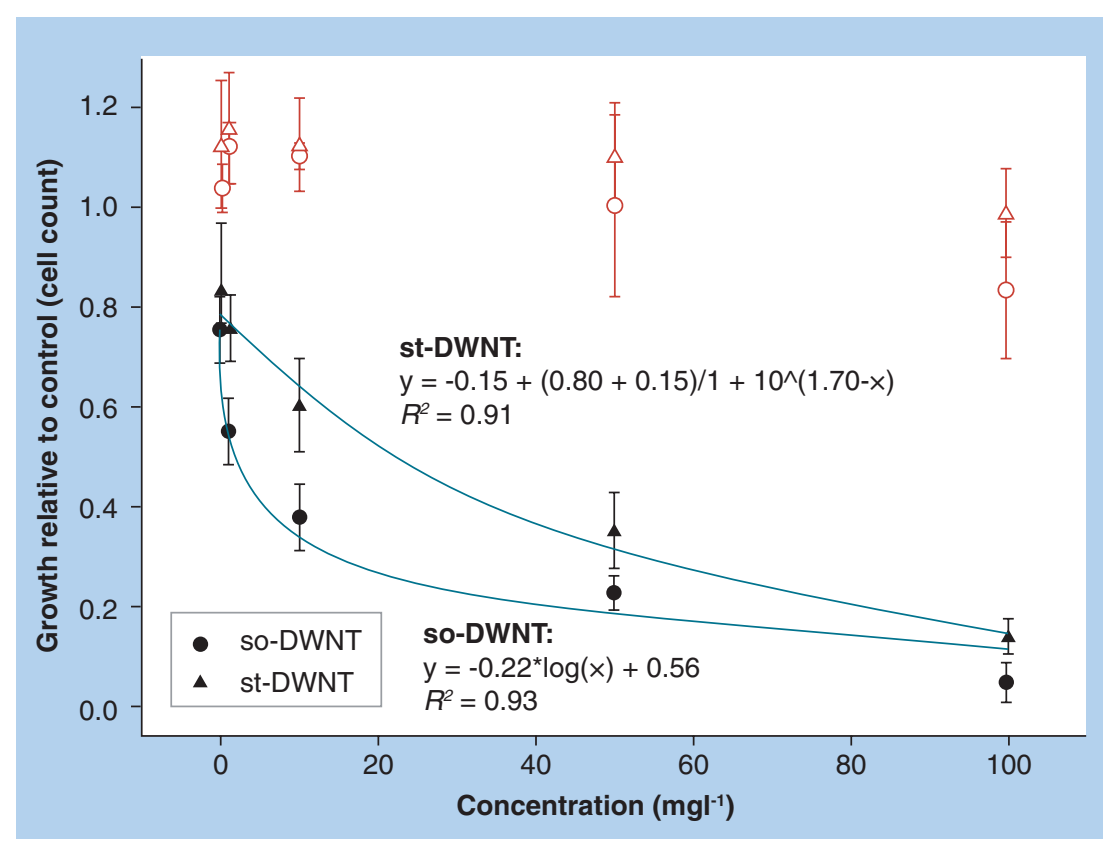

Figure 3. Relative growth of Thalassiosira pseudonana (mean \pm 1 standard deviation) exposed to different nominal concentrations of sonicated double-walled carbon nanotubes (open circles) and stirred double-walled carbon nanotubes (open triangles). These results are compared with the light-blocking effect control groups for so-DWNTs (circles) and st-DWNTs (triangles)

so-DWNT: Sonicated double-walled carbon nanotube; st-DWNT: Stirred double-walled carbon nanotube.
To ensure consistency of exposure, copepods were placed into new microwells containing fresh tests solutions and algal food every $96 \mathrm{~h}$. Copepods were monitored daily for life stage, mortality, development and sex determination. When the copepods reached copepodid stage 5 , male and female copepods were paired up and mated within each replicate for each treatment. Lifecycle testing was terminated after the release of the second brood of eggs from each mating pair. Test periods for individual microplate bioassays ranged from 20 to 30 days to account for treatment-specific developmental delays. All tests were conducted at $25 \pm 0.5^{\circ} \mathrm{C}, 30 \pm 0.5 \%, \mathrm{pH} 7.8-8.0$ and a 16:8 h photoperiod.

Mortality, duration of larval development (from $<24 \mathrm{~h}$ nauplii to develop into copepodid stage 1), time to first reproduction (from $<24 \mathrm{~h}$ nauplii to the development of the first egg brood) and the intrinsic rate of increase $\left(r_{\mathrm{m}}\right)$ were used as end points. The $r_{\mathrm{m}}$ integrates mortality, reproductive output and frequency; it was computed using the method described in Kwok et al. and is an estimate of the intrinsic population growth rate [20].

\section{Histological investigation}

Copepods were found to ingest and defecate CNTs in an earlier study [11]. In this study, TEM was used to confirm if DWNTs can penetrate into the gut and cuticle cells of T. japonicus after exposure. Ten T. japonicus were exposed for 7 days to either $100 \mathrm{mg} / \mathrm{l}$ of so-DWNTs or $100 \mathrm{mg} / \mathrm{l}$ of st-DWNTs. Sample preparation was modified from Au et al. [22]. After the exposure period, the copepods were fixed under room temperature in a solution containing $2 \%$ paraformaldehyde, $2.5 \%$ glutaraldehye, $0.05 \%$ calcium chloride $0.4 \mathrm{M}$ sucrose in $0.1 \mathrm{M}$ cacodylate buffer at $\mathrm{pH}$ 7.6. Samples were decalcified with 5\% EDTA in $0.1 \mathrm{M}$ cacodylate buffer with $0.2 \mathrm{M}$ sucrose. After fixing, samples were rinsed in buffer and distilled water, dehydrated in a graded ethanol series and acetone, then infiltrated and embedded in Spurr's resin. Samples were postfixed in $2 \%$ osmium tetroxide $\left(\mathrm{OsO}_{4}\right)$ in $0.1 \mathrm{M}$ cacodylate buffer in the dark for $3 \mathrm{~h}$.

Five of the ten individuals were randomly chosen and semi-thin dorsal-ventral sections (thickness $0.3 \mathrm{~mm}$ ) stained with toluidine blue were prepared for orienting the tissue for ultrathin sectioning. Ultrathin sections $(75 \mathrm{~nm})$ were prepared with an ultramicro- tone (Leica Reichert Ultracut UCT, Austria) individuals developed from eggs will take at most 21 days to deposit their first egg brood [21]. 
with a diamond knife (Diatome, Switzerland) and double stained with Reynold's lead citrate and uranyl acetate. Three random sections per individual were examined under TEM at $80 \mathrm{kV}$. The gut and cuticle of the copepods were examined in each section, as they represent the major part in contact with the test materials via the dietary and dermal exposure pathways, respectively.

\section{- Medaka larvae test}

The medaka fish $O$. melastigma has been proposed as a saltwater fish model for ecotoxicology [23]. O. melastigma is small and easy to culture and breed, exhibits uniform growth, completes its whole lifecycle in seawater and has a similar biology to its freshwater counterpart Oryzias latipes [23]. Newly born $(<16 \mathrm{~h}$ posthatch) fish larvae were collected and maintained until $48 \mathrm{~h}$ posthatch. The $48 \mathrm{~h}$ posthatch larvae were individually placed in a $5 \times 5$ compartment square petri dish and exposed to various levels of DWNTs $(10,50$ and $100 \mathrm{mg} / \mathrm{l})$. Fish were fed with artemia larvae (24 h old) daily ad libitum and test solutions were renewed every $48 \mathrm{~h}$. Survival of fish was recorded daily. At days 1, 4, 7, 10 and 14 of exposure, photos of all individual fish of all treatments were taken and their total lengths were measured using software Image J [105]. Tests were conducted at $25 \pm 0.5^{\circ} \mathrm{C}, 30 \pm 0.5 \%$, $\mathrm{pH} 7.8-8.0$ and a 16:8 h photoperiod.

\section{- Statistical analysis}

For each test, one-way analysis of variance (ANOVA) followed by Dunnett's test was used to determine the no observed effect concentration and lowest observed effect concentration of each of the end points compared with the control. Proportion data were arcsine transformed before running the ANOVA [24]. For conciseness, length data of medaka of different treatments were only compared at day 7 and day 14 using ANOVA. Bonferroni correction for multiple testing was used [24], and for cases with significant effects (after the Bonferroni correction), their corresponding no observed effect concentration and lowest observed effect concentration were determined. Regression analyses were carried out for growth data of the algae, and mortality data of the copepods against the concentration of DWNTs and 50\% effect concentration $\left(\mathrm{EC}_{50}\right)$ values were calculated using appropriate parametric regression models. Analysis of covariance (ANCOVA) was conducted to compare the toxicity between
so-DWNTs and st-DWNTs using the measured end points as the dependent variable, the dispersion method as the fixed factor and concentration as the covariate.

\section{Results}

\section{Aggregation size distributions}

Double-walled carbon nanotubes aggregated in filtered artificial seawater and representative TEM images of DWNT aggregates are shown in Figure 2 at two different magnifications. Aggregate size distributions of the DWNTs determined by TEM showed that so-DWNTs had a significantly smaller aggregate size than st-DWNTs (Figure 2E; Mann-Whitney test:

\begin{tabular}{|c|c|c|c|c|c|c|}
\hline $\begin{array}{l}\text { Test } \\
\text { species }\end{array}$ & End point & $F$ value & p-value & $\begin{array}{l}\text { LOEC } \\
\left(\mathrm{mg} \mathrm{l}^{-1}\right)\end{array}$ & $\begin{array}{l}\text { NOEC } \\
\left(\mathrm{mg} \mathrm{l}^{-1}\right)\end{array}$ & $\begin{array}{l}\mathrm{EC}_{50} \\
\left(\mathrm{mg} \mathrm{l}^{-1}\right)\end{array}$ \\
\hline \multicolumn{7}{|c|}{ so-DWNT } \\
\hline \multirow[t]{2}{*}{ Diatom } & Algal growth ${ }^{+}$ & $F_{5,18}=95.0^{\dagger}$ & $<0.001^{\dagger}$ & $0.1^{\dagger}$ & $\mathrm{ND}^{+}$ & $1.86^{\dagger}$ \\
\hline & $\begin{array}{l}\text { Algal growth } \\
\text { (light blocking) }\end{array}$ & $F_{5,18}=5.1$ & $<0.01$ & ND & ND & No fit ${ }^{\ddagger}$ \\
\hline \multirow[t]{5}{*}{ Copepod } & Total mortality $^{\dagger}$ & $F_{649}=7.3^{+}$ & $<0.001^{\dagger}$ & $50^{+}$ & $30^{+}$ & No fit ${ }^{\dagger \neq}$ \\
\hline & $\begin{array}{l}\text { Larval } \\
\text { mortality }^{\dagger}\end{array}$ & $F_{6,49}=10.7^{\dagger}$ & $<0.001^{\dagger}$ & $30^{+}$ & $10^{+}$ & No fit ${ }^{\dagger \ddagger}$ \\
\hline & $\begin{array}{l}\text { Larval } \\
\text { development }\end{array}$ & $F_{6,49}=4.0$ & $<0.01$ & ND & ND & ND \\
\hline & $\begin{array}{l}\text { Time to first } \\
\text { reproduction }\end{array}$ & $F_{6,49}=152^{\dagger}$ & $<0.001^{+}$ & $0.1^{\dagger}$ & $\mathrm{ND}^{+}$ & $\mathrm{ND}^{+}$ \\
\hline & $\begin{array}{l}\text { Intrinsic rate of } \\
\text { increase }\end{array}$ & $F_{6,49}=33.4$ & $<0.001$ & 0.1 & ND & No fit ${ }^{\ddagger}$ \\
\hline \multirow[t]{3}{*}{ Medaka } & Mortality & $F_{3,8}=8.8$ & $<0.01$ & ND & ND & ND \\
\hline & Length at d7 & $F_{3,8}=9.3$ & $<0.01$ & ND & ND & ND \\
\hline & Length at $\mathrm{d} 14^{+}$ & $F_{3,8}=16.6^{+}$ & $<0.001^{\dagger}$ & $10^{+}$ & $\mathrm{ND}^{+}$ & $\mathrm{ND}^{+}$ \\
\hline \multicolumn{7}{|l|}{$s t-D W N T$} \\
\hline \multirow[t]{2}{*}{ Diatom } & Algal growth ${ }^{+}$ & $F_{5,18}=46.0^{\dagger}$ & $<0.001^{\dagger}$ & $0.1^{+}$ & $\mathrm{ND}^{+}$ & $22.7^{+}$ \\
\hline & $\begin{array}{l}\text { Algal growth } \\
\text { (light blocking) }\end{array}$ & $F_{5,18}=2.2$ & $>0.05$ & ND & ND & No fit ${ }^{\ddagger}$ \\
\hline \multirow[t]{5}{*}{ Copepod } & Total mortality & $F_{6,49}=3.8$ & $<0.01$ & ND & ND & No fit ${ }^{\ddagger}$ \\
\hline & $\begin{array}{l}\text { Larval } \\
\text { mortality }^{\dagger}\end{array}$ & $F_{6,49}=10.9^{\dagger}$ & $<0.001^{\dagger}$ & $100^{+}$ & $50^{+}$ & No fit ${ }^{\dagger \ddagger}$ \\
\hline & $\begin{array}{l}\text { Larval } \\
\text { development }\end{array}$ & $F_{6,49}=2.4$ & $<0.05$ & ND & ND & ND \\
\hline & $\begin{array}{l}\text { Time to first } \\
\text { reproduction }\end{array}$ & $F_{6,49}=51.5^{\dagger}$ & $<0.001^{\dagger}$ & $10^{+}$ & $1^{+}$ & $\mathrm{ND}^{+}$ \\
\hline & $\begin{array}{l}\text { Intrinsic rate of } \\
\text { increase }^{+}\end{array}$ & $F_{6,49}=20.1^{\dagger}$ & $<0.001^{\dagger}$ & $10^{+}$ & $1^{+}$ & No fit ${ }^{\dagger \neq}$ \\
\hline \multirow[t]{3}{*}{ Medaka } & Mortality & $F_{3,8}=3.0$ & $>0.05$ & ND & ND & ND \\
\hline & Length at $d 7$ & $F_{3,8}=1.3$ & $>0.05$ & ND & ND & ND \\
\hline & Length at d14 & $F_{3,8}=7.6$ & $<0.01$ & ND & ND & ND \\
\hline \multicolumn{7}{|c|}{$\begin{array}{l}\text { 'Indicates cases with a significant effect after Bonferroni correction for multiple tests ( } \alpha=0.05) \text {. } \\
\text { "No fit: No significant regression model could be fitted. } \\
\text { d: Day; EC } C_{50} \text { : Effect concentration } 50 \% \text {; LOEC: Lowest observed effect concentrations; ND: Not } \\
\text { determined; NOEC: No observed effect concentrations; so-DWNT: Sonicated double-walled carbon } \\
\text { nanotube; st-DWNT: Stirred double-walled carbon nanotube. }\end{array}$} \\
\hline
\end{tabular}




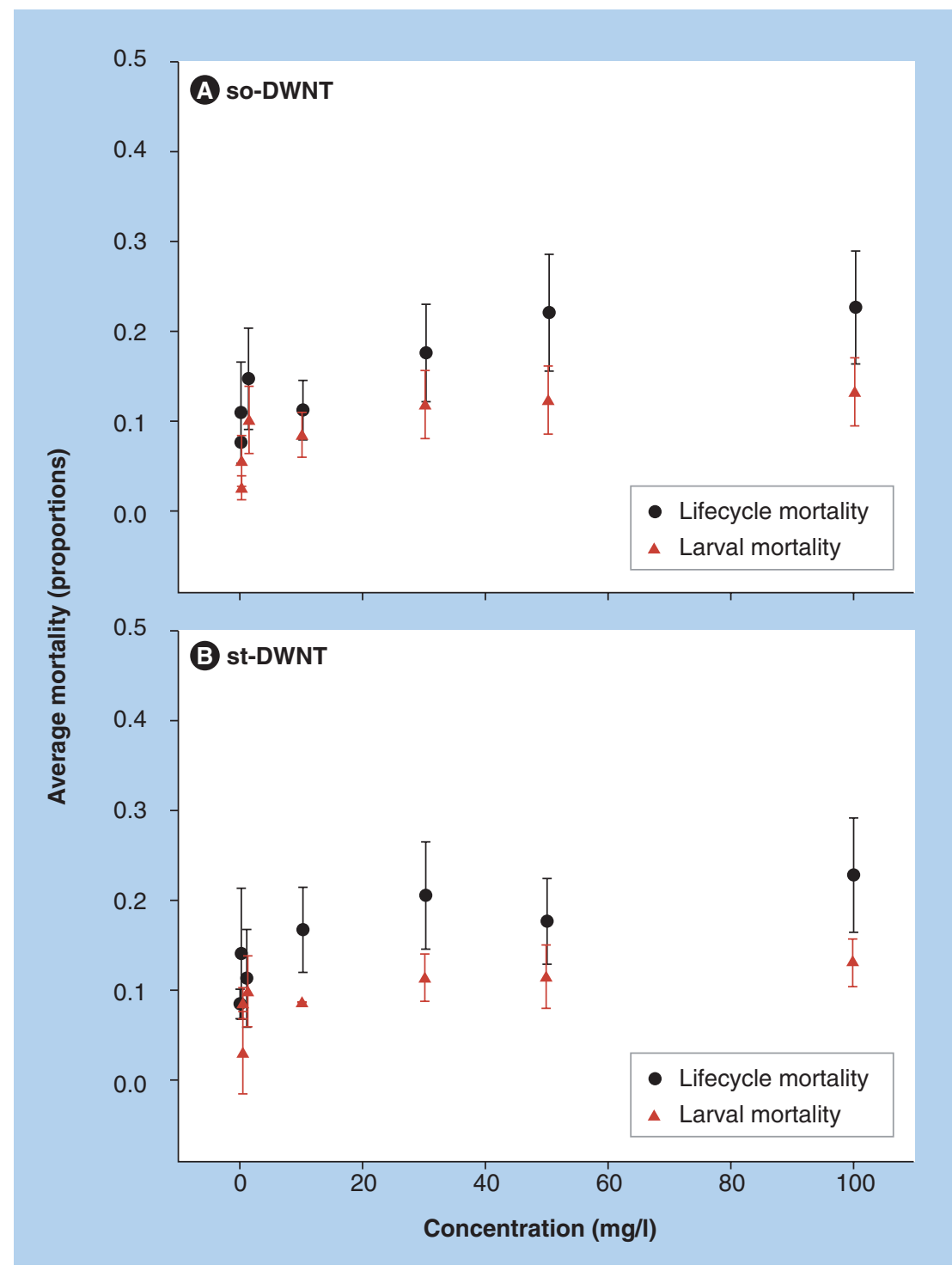

Figure 4. Mortality (mean \pm 1 standard deviation) of Tigriopus japonicus exposed to different concentrations of (A) so- and (B) st-DWNTs. so-DWNT: Sonicated double-walled carbon nanotube; st-DWNT: Stirred double-walled carbon nanotube. that DWNTs were opaque and dark in color (Figure 1), no significant growth inhibitory effects were detected in the light-blocking controls for st-DWNT and so-DWNTs (Figure 3 \& Table 1).

\section{Copepod lifecycle test}

The mortality of the copepod T. japonicus exposed to DWNTs was generally low. Even in the highest concentration treatments of both dispersion methods, less than $30 \%$ mortality was recorded (FIGURE 4). A significant increase in total lifecycle mortality, compared with that of the water control, was observed at 50 and $100 \mathrm{mg}$ DWNT/l regardless of the dispersion method used (Figure 4 \& Table 1). Most of these mortality events occurred during the larval period (from $<24$-h-old nauplii to copepodid stage 1 ). In general, so-DWNTs were more toxic than stDWNTs to the copepod (Figure 4). The former caused a significantly higher larval mortality at 30,50 and $100 \mathrm{mg} / \mathrm{l}$, but only the latter resulted in a significantly higher larval mortality at $100 \mathrm{mg} / \mathrm{l}$ (Figure 4). The dose-response relationships of st- and so-DWNTs were unclear and no parametric regression model could be appropriately fitted for toxicity data generated from either DWNT $(\mathrm{p}>0.05)$.

Exposure to so-DWNTs and so-DWNTs did not affect larval development (Figure 5A \& TABLE 1) but delayed the first reproduction by $1-3$ days, depending on the concentration and dispersion method (Figure 5). For st-DWNTs, a significant delay of first reproduction was detected from $10 \mathrm{mg} / \mathrm{l}$ (TABle 1). A higher impact by so-DWNTs was detected, as the significant delay of first reproduction was detected from $0.1 \mathrm{mg} / \mathrm{l}$ (Figure 5).

The $r_{m}$ was the most sensitive end point to DWNT exposure. A significant decrease of $r$ was found at $10 \mathrm{mg} / \mathrm{l}$ for st-DWNTs and $0.1 \mathrm{mg} / \mathrm{l}$ or more for so-DWNTs (Table 1). Regardless of the dispersion method, the $r_{\mathrm{m}}$ of the copepods at the highest DWNT concentration decreased to approximately half of that of the control (Figure 5). Toxicities of DWNTs dispersed by the two different methods were compared using ANCOVA. Of all the end points measured, only time to first reproduction showed a significant interaction between the dispersion method and concentration of DWNTs $\left(F_{1,108}=52.0 ; \mathrm{p}<0.001\right)$. supporting the hypothesis that so-DWNTs were more toxic (Figure 3) to the algal [than st-DWNTs]. The difference in their toxicity was also revealed by their $\mathrm{EC}_{50}$ values (so-DWNT: $1.86 \mathrm{mg} / \mathrm{l}$; st-DWNT: $22.7 \mathrm{mg} / \mathrm{l}$; Table 1). Despite the fact

\section{- Histological investigation}

Light microscopy observation of T. japonicus during the lifecycle experiment indicated that T. japonicus clearly ingested DWNTs. Distinct 
black aggregates were evidenced only inside the gut of exposed animals (Figure 6A) and the same black aggregates were also observed in their fecal pellets (Figure 6B) (and never in the case of the control animals, as in Figure 6C), suggesting that at least part of the ingested DWNTs were removed by defecation. DWNT aggregates were also evidenced in the lumen of the mid-gut region by TEM (Figure 6D \& E). These findings concur with a previous study on copepods exposed to SWNTs [11]. However, in TEM analysis, DWNTs were not evidenced in either the cuticle or the cuticle cells in all examined slides (data not shown).

\section{Medaka larval test}

There were no significant differences in mortality between medaka larvae exposed to soDWNTs and st-DWNTs (Figure $7 \&$ Table 1). Nonetheless, the growth (in terms of total length) of the fish exposed to so-DWNTs was significantly lowered after 14 days at 50 and $10 \mathrm{mg} / \mathrm{l}$, respectively (Figure $8 \&$ Table 1 ). By contrast, st-DWNTs led to significant inhibition on the growth of the medaka only at $100 \mathrm{mg} / \mathrm{l}$ after 14 days of exposure (Figure 8B \& Table 1). No apparent malformation was observed in medaka larvae exposed to either type of DWNT.

In summary, exposure to DWNTs resulted in growth inhibition of $T$. pseudonana with $\mathrm{EC}_{50} \mathrm{~s}$ of 1.86 and $22.7 \mathrm{mg} / \mathrm{l}$ for so- and stDWNTs, respectively. The population growth of $T$. japonicus was significantly decreased at $0.1 \mathrm{mg} / \mathrm{l}$ or more for so-DWNTs and $10 \mathrm{mg} / \mathrm{l}$ for st-DWNTs, attributable to increased mortality and impaired reproduction. Growth inhibition in $O$. melastigma was observed at $10 \mathrm{mg} / \mathrm{l}$ or more for so-DWNTs and $100 \mathrm{mg} / \mathrm{l}$ for st-DWNTs. Consistently, so-DWNTs were significantly more toxic than st-DWNTs across all test species.

\section{Discussion}

This study demonstrated that chronic exposure to DWNTs led to a significant decline of population growth of the copepod T. japonicus, and detectable growth inhibition on the diatom T. pseudonana and the medaka larvae O. melastigma. DWNTs have different toxicities towards the three test marine species, with a higher toxicity observed towards the copepod, followed by the diatom and the medaka. In contrast to the current chronic toxicity test results, short-term lethal-based acute toxicity tests, which are often used to understand CNT
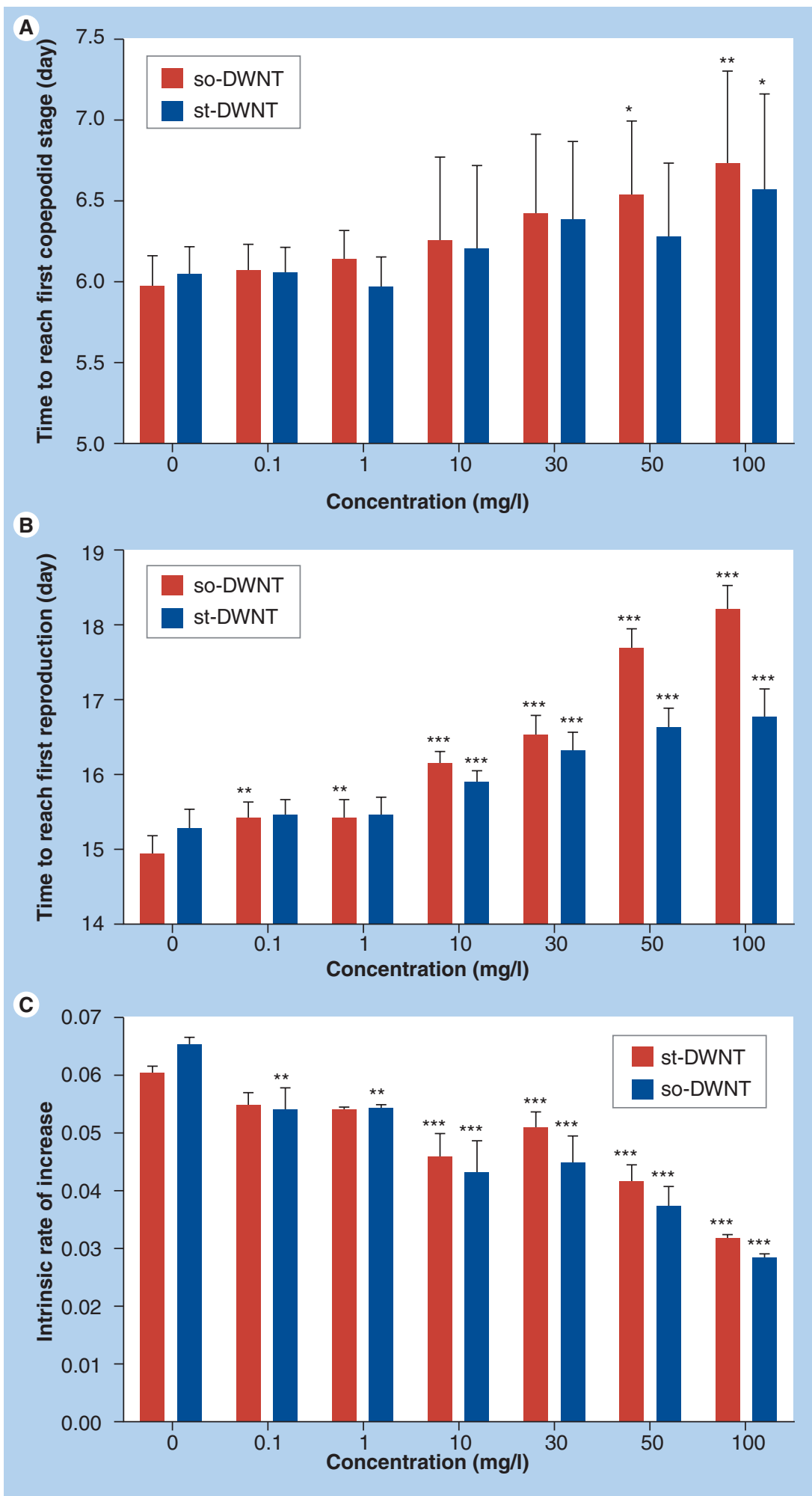

Figure 5. Development time and intrinsic rate of increase (mean +1 standard deviation) of Tigriopus japonicus exposed to different concentrations of stirred and sonicated double-walled carbon nanotubes.

(A) Larval development time from less than 24 -h-old nauplii to copepodid stage;

(B) time from less than $24 \mathrm{~h}$ to first reproduction; and (C) intrinsic rate of increase. Asterisks indicate different levels of statistical difference from the seawater control: ${ }^{*} p<0.05 ;{ }^{*} p<0.01 ;{ }^{* *} p<0.001$ (Dunnett's multiple comparison test). so-DWNT: Sonicated double-walled carbon nanotube; st-DWNT: Stirred double-walled carbon nanotube. 
toxicity in previous studies (see [8]), are clearly not sensitive enough to detect such ecologically relevant sublethal toxicity effects.
Previous researchers have suggested that CNT toxicity was primarily caused by oxidative stress in in vitro studies using mammalian

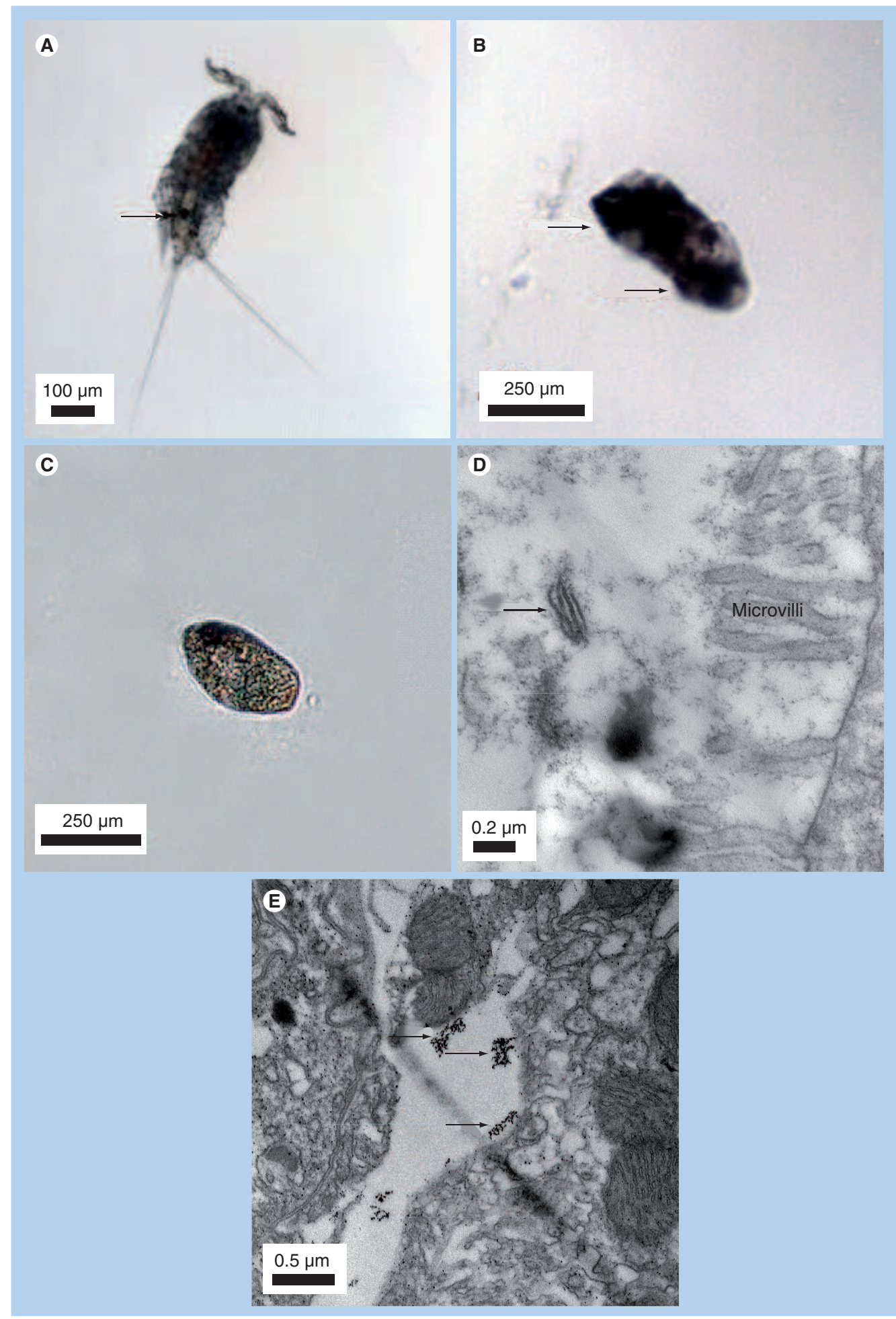

Figure 6. The results of histological investigation of the fate of double-walled carbon nanotubes in the copepod Tigriopu japonicus. (A) Ingested double-walled carbon nanotubes (DWNTs) visible as black clump inside the gut of Tigriopus japonicus. (B) DWNT agglomerates visible as black aggregates in fecal pellet of $T$. japonicus. (C) Fecal pellet of a control copepod. (D \& E) Transmission electron microscope images of DWNT agglomerates inside the gut of $T$. japonicus. Arrows indicate positions of DWNT agglomerates. 
cell cultures $[25,26]$. In a full lifecycle chronic toxicity study, Templeton et al. suggested that CNTs can cause oxidative stress and thus toxicity in the estuarine copepod A. tenuiremis [11]. Although some researchers suggested that oxidative stress induced by CNTs may be caused by the presence of metal contaminants (or impurities) in the CNT instead [26,27], this is unlikely the cause of oxidative stress observed in the present study. More likely the reason is that the cobalt present in the DWNTs was carbon encapsulated and therefore unlikely to be bioavailable $[3,19]$.

Based on the current results, DWNTs are possibly able to induce both oxidative and physical stress, which may result in the initiation of defense mechanisms. This may explain the adverse developmental and reproductive effects of DWNTs observed in T. japonicus. Induction of defense mechanisms may divert energy otherwise used for reproduction or development [28]. Confusion of DWNTs with food particles may also have contributed to the adverse effects previously mentioned by lowering the food intake efficiency of $T$. japonicus, as this was also found in other copepod [11] as well as with similar DWNT samples in the case of amphibians $[29,30]$. The present results also confirmed that DWNTs were not only ingested by $T$. japonicus but also observed inside their gut cells. Meanwhile, gill damage or blockage by DWNTs [10] may be an alternative explanation to DWNT toxicity observed in the medaka fish.

To date, there are no published studies on CNT toxicity to marine algae. This is the first study demonstrating that DWNTs can lead to a relatively high (growth inhibition) toxicity to the diatom $T$. pseudonana, highlighting the need for further studies in this area. Van Hoecke et al. reported that silica nanoparticles can adhere to the outer cell surface of algal cells and hence cause physical disruption on cell surface membrane functions and reduction of light penetration to the cell, resulting in growth inhibition [31]. More research will be required to understand the toxic mechanism of DWNTs to microalgae, such as the diatom.

As shown in this study (Figure 2), dispersing DWNTs in water by sonication (so-DWNTs) resulted in smaller aggregate size when compared with dispersion by stirring (st-DWNTs). The median aggregation size $\left(0.89 \mu \mathrm{m}^{2}\right)$ of so-DWNTs was much smaller than that of st-DWNTs $\left(21.8 \mu \mathrm{m}^{2}\right)$. The distinctive aggregate size may offer an explanation to the differences in toxicities of so-DWNTs and stDWNTs. Consistently, so-DWNTs were found to be more toxic to the three test organisms than st-DWNTs. Indeed, sonication has been suggested to increase the toxicity of SWNTs [32]. However, the cause of this increased toxicity, whether by better dispersion in the solution, or potential alteration of CNT structure or surface properties, will require further investigation. DWNTs dispersed by stirring should represent a more environmentally realistic estimate of their toxicity. The influence of the addition of a surfactant was not discussed here, as it was not desirable to interfere with the intrinsic toxicity of the surfactant itself. However, the presence of surfactants (either natural [33] or man-made [34]) cannot be ruled out and should play an important role in terms of separation of the CNTs (e.g., debundling and dispersion of aggregates) and stabilization of the obtained suspensions, even at a very low concentration [34].

\section{Conclusion}

Sonication could better disperse DWNTs in artificial marine water than stirring. The median aggregation size $\left(0.89 \mu \mathrm{m}^{2}\right)$ of so-DWNTs was smaller than that of st-DWNTs $\left(21.8 \mu \mathrm{m}^{2}\right)$. Chronic toxicity of so-DWNTs was also higher than st-DWNT to the diatom T. pseudonana, copepod T. japonicus and medaka O. melastigma. Exposure to DWNTs led to growth inhibition of

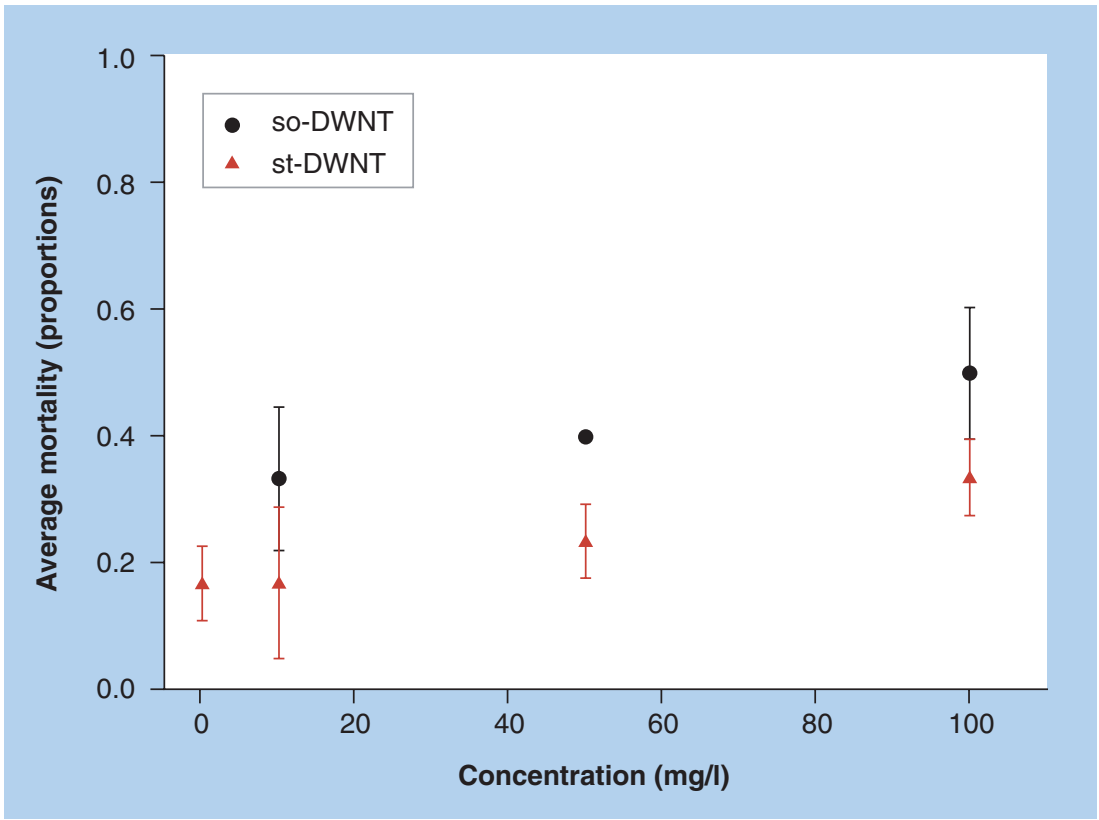

Figure 7. Mortality of medaka fish larvae (mean \pm 1 standard deviation) exposed to different concentrations of stirred and sonicated double-walled carbon nanotubes.

so-DWNT: Sonicated double-walled carbon nanotube; st-DWNT: Stirred double-walled carbon nanotube. 


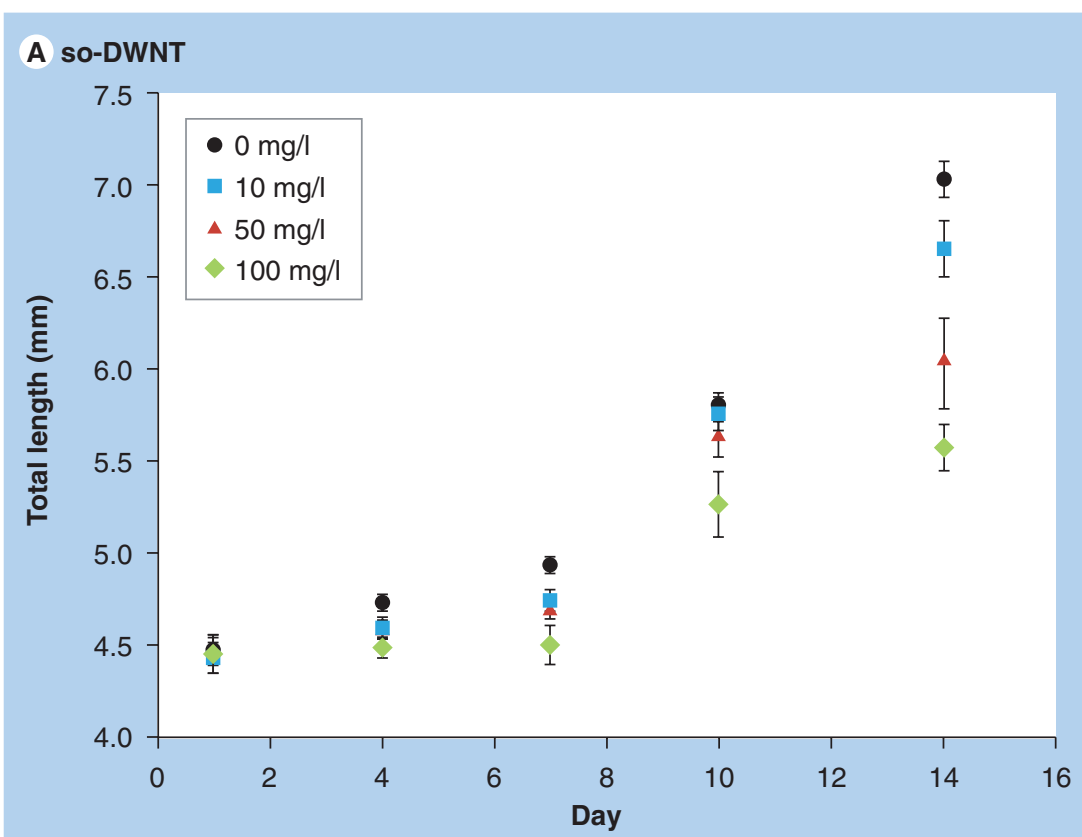

\section{B st-DWNT}

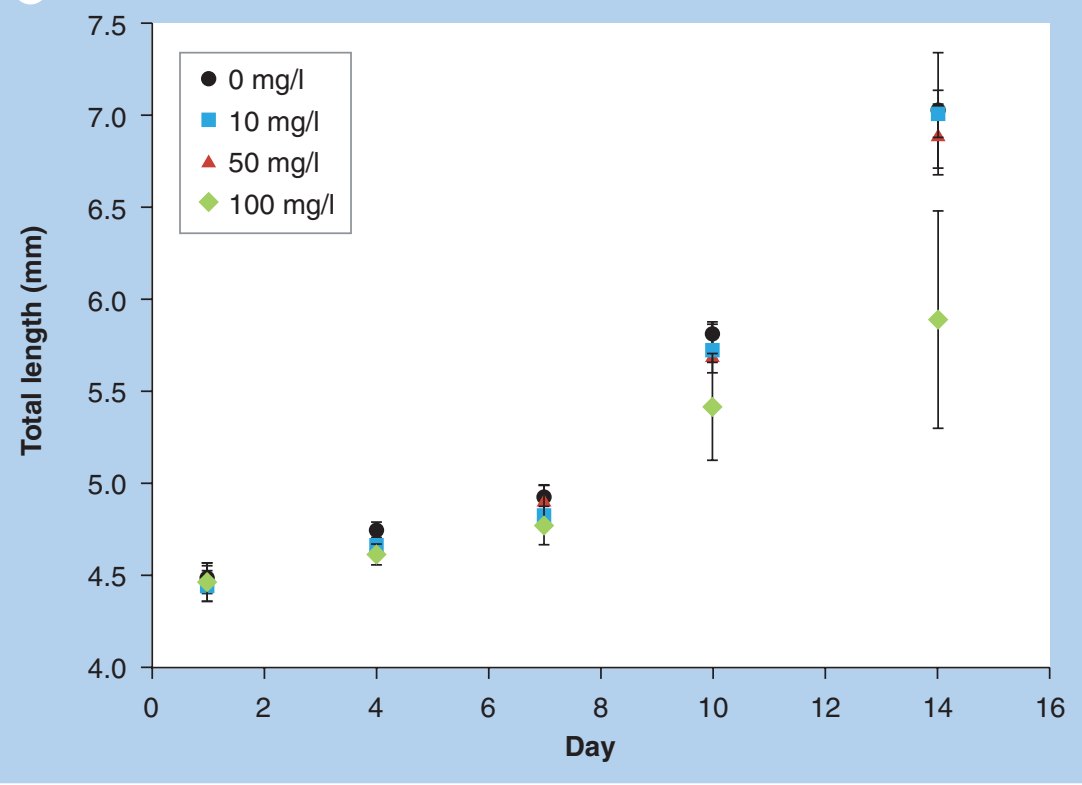

Figure 8. The growth profiles (in terms of total length) of the medaka larvae (mean \pm 1 standard deviation) over 14 days of exposure to different concentrations of (A) sonicated double-walled carbon nanotubes and (B) stirred double-walled carbon nanotubes.

so-DWNT: Sonicated double-walled carbon nanotube; st-DWNT: Stirred double-walled carbon nanotube.
T. pseudonana with $\mathrm{EC}_{50} \mathrm{~s}$ of 1.86 and $22.7 \mathrm{mg} / \mathrm{l}$ for so- and st-DWNTs, respectively. Population growth of T. japonicus was reduced by $0.1 \mathrm{mg} / \mathrm{l}$ or more for so-DWNTs and $10 \mathrm{mg} / \mathrm{l}$ for stDWNTs. Given that so-DWNTs are consistently significantly more toxic than st-DWNTs, the use of sonication probably leads to over estimation of the ecotoxicity of DWNTs.

\section{Future perspective}

The search for dispersion methods that produce environmentally realistic data regarding the aggregation and structure of nanomaterials will be a key area of research and a prerequisite to the understanding of ecotoxicity of nanomaterials.

\section{Acknowledgements}

The authors would like to thank Helen Leung and Cecily Law for their technical support throughout the project.

\section{Financial \& competing interests disclosure}

This research is partly funded by the Area of Excellence Scheme under the University Grants Committee (Project No. AoE1528 P-04/2004) and partially supported by a grant from the Research Grants Council of the Hong Kong Special Administrative Region Government, China (Project No. CityU 160108). Kevin Kwok thanks HKU for partially supporting his PhD studentship. Emmanuel Flahaut's laboratory is part of a common laboratory with Arkema FR and shares an academic relationship with this company. The authors have no other relevant affiliations or financial involvement with any organization or entity with a financial interest in or financial conflict with the subject matter or materials discussed in the manuscript apart from those disclosed.

No writing assistance was utilized in the production of this manuscript.

\section{Ethical conduct of research}

The authors state that they have obtained appropriate institutional review board approval or have followed the principles outlined in the Declaration of Helsinki for all buman or animal experimental investigations. In addition, for investigations involving human subjects, informed consent has been obtained from the participants involved.

\section{Bibliography}

Papers of special note have been highlighted as: " of interest

"n of considerable interest

1 Oberdörster G, Oberdörster E, Oberdörster J: Nanotoxicology: an emerging discipline evolving from studies of ultrafine particles. Environ. Health. Perspect. 113, 823-839 (2005).
2 Baughman RH, Zakhidov AA, de Heer WA: Carbon nanotubes - the route toward applications. Science 297, 787-792 (2002).

3 Flahaut E, Bacsa R, Peigney A, Lauret C: Gram-scale CCVD synthesis of doublewalled carbon nanotubes. Chem. Commun. 2003, 1442-1443 (2003).
Lyu SC, Lee TJ, Yang CW, Lee JC: Synthesis and characterization of high-quality double-walled carbon nanotubes by catalytic decomposition of alcohol. Chem. Commun. 21(12), 1404-1405 (2003).

5 Ruparelia JP, Duttagupta SP, Chatterjee AK, Mukherji S: Potential of carbon nanomaterials for removal of heavy metals from water. Desalination 232, 145-156 (2008). 
6 Rao GP, Lu C, Su F: Sorption of divalent metal ions from aqueous solution by carbon nanotubes: a review. Sep. Purif. Technol. 58, 224-231 (2007).

7 Helmus MN: The need for rules and regulations. Nat. Nanotechnol. 2, 333-334 (2007).

8 Cheng J, Flahaut E, Cheng SH: Effect of carbon nanotubes on developing zebrafish embryos. Environ. Toxicol. Chem. 26, 708-716 (2007).

- - Demonstrates that large carbon nanotube aggregate size can limit its bioavailability to zebrafish embryos.

9 Donaldson K, Aitken R, Tran L et al.: Carbon nanotubes: a review of their properties in relation to pulmonary toxicology and workplace safety. Toxicol. Sci. 92, 5-22 (2006).

10 Smith CJ, Shaw BJ, Handy RD: Toxicity of single walled carbon nanotubes to rainbow trout, (Oncorhynchus mykiss): respiratory toxicity, organ pathologies, and other physiological effects. Aquat. Toxicol. 82, 94-109 (2007).

11 Templeton RC, Ferguson PL, Washburn KM, Scrivens WA, Chandler GT: Life-cycle effects of single-walled carbon nanotubes (SWNTs) on an estuarine meiobenthic copepod. Environ. Sci. Technol. 40, 7387-7393 (2006).

"II An important study showing population level effect of carbon nanotubes.

12 Lam CW, James JT, McCluskey R, Hunter RL: Pulmonary toxicity of single-wall carbon nanotubes in mice 7 and 90 days after intratracheal instillation. Toxicol. Sci. 77, 126-134 (2004).

13 Warheit DB, Laurence BR, Reed KL, Roach DH, Reynolds GAM, Webb TR: Comparative pulmonary toxicity assessment of single-wall carbon nanotubes in rats. Toxicol. Sci. 77, 117-125 (2004).

14 Thess A, Lee R, Nikolaev P et al.: Crystalline ropes of metallic carbon nanotubes. Science 273, 483-487 (1996).

15 Handy RD, Shaw BJ: Toxic effects of nanoparticles and nanomaterials: implications for public health, risk assessment and the public perception of nanotechnology. Health Risk. Soc. 9, 125-144 (2007).

16 Ham TH, Choi YS, Chung IJ An explanation of dispersion states of single-walled carbon nanotubes in solvents and aqueous surfactant solutions using solubility parameters. J. Colloid. Interf. Sci. 286, 216-223 (2005).

- Provides important information regarding aggregation of carbon nanotubes in natural waters.
17 Raja PMV, Connolley J, Ganesan GP et al.: Impact of carbon nanotube exposure, dosage and aggregation on smooth muscle cells. Toxicol. Lett. 169, 51-63 (2007).

18 Wick P, Manser P, Limbach LK et al.: The degree and kind of agglomeration affect carbon nanotube cytotoxicity. Toxicol. Lett. 168, 121-131 (2007).

19 Flahaut E, Agnoli F, Sloan J, O’Connor C, Green MLHL: CCVD synthesis and characterization of cobalt-encapsulated nanoparticles. Chem. Mater. 14, 2553-2558 (2002).

20 Kwok KWH, Leung KMY, Bao VWW, Lee J-S: Copper toxicity in the marine copepod Tigriopus japonicus: low variability and high reproducibility of repeated acute and life-cycle tests. Mar. Pollut. Bull. 57, 632-636 (2008).

21 Raisuddin S, Kwok KWH, Leung KMY, Schlenk D, Lee J-S: The copepod Tigriopus: a promising marine model organism for ecotoxicology and environmental genomics. Aquat. Toxicol. 83, 161-173 (2007).

22 Au DWT, Wu RSS, Zhou BS, Lam PKS: Relationship between ultrastructural changes and EROD activities in liver of fish exposed to benzo[a]pyrene. Environ. Pollut. 104, 235-247 (1999).

23 Kong RY, Giesy JP, Wu RS et al.: Development of a marine fish model for studying in vivo molecular responses in ecotoxicology. Aquat. Toxicol. 86, 131-141 (2008).

24 Zar JH: Biostatistical Analysis (4th Edition). Prentice-Hall International Press, NJ, USA (1999).

25 Shvedova AA, Castranova V, Kisin ER et al.: Exposure to carbon nanotube material: assessment of nanotube cytotoxicity using human keratinocyte cells. J. Tox. Env. Health A 66, 1909-1926 (2003).

26 Pulskap K, Diabatè S, Krug HF: Carbon nanotubes show no sign of acute toxicity but induce intracellular reactive oxygen species in dependence on contaminants. Toxicol. Lett. 168, 58-74 (2007)

27 Kegan VE, Tyurina YY, Tyurin VA et al: Direct and indirect effects of single walled carbon nanotubes on RAW 264.6 macrophages: role of iron. Toxicol. Lett. 165, 88-100 (2006).

28 Kwok KWH, Grist EPM, Leung KMY: Acclimation effect and fitness cost of copper resistance in the marine copepod Tigriopus japonicus. Ecotox. Environ. Safe. 72, 358-364 (2009).
29 Mouchet F, Landois P, Sarremejean E et al.: Characterisation and in vivo ecotoxicity evaluation of double-wall carbon nanotubes in larvae of the amphibian Xenopus laevis. Aquat. Toxicol. 87, 127-137 (2008).

30 Mouchet F, Landois P, Flahaut E, Pinelli E, Gauthier L: Assessment of the potential in vivo ecotoxicity of double-walled carbon nanotubes (DWNTs) in water, using the amphibian Ambystoma mexicanum. Nanotoxicology 1, 149-156 (2007).

31 Van Hoecke K, de Schamphelaere KAC, van der Meeren P, Lucas S, Janssen CR: Ecotoxicity of silica nanoparticles to the green alga Pseudokirchneriella subcapitata: importance of surface area. Environ. Toxicol. Chem. 27, 1948-1957 (2008).

32 Oberdörster E, Zhu S, Blickley TM, McClellan-Green P, Haasch ML: Ecotoxicology of carbon-based engineered nanoparticles: effects of fullerene $\left(\mathrm{C}_{60}\right)$ on aquatic organisms. Carbon 44, 1112-1120 (2006).

33 Hyung H, Fortner JD, Hughes JB, Kim JH: Natural organic matter stabilizes carbon nanotubes in the aqueous phase. Environ. Sci. Technol. 41, 179-184 (2007).

34 Datsyuk V, Landois P, Fitremann J et al.: Double-walled carbon nanotube dispersion via surfactant substitution. J. Mater. Chem. 19, 2729-2736 (2009).

\section{Websites}

101 SciFinder Scholar search system: Search for the term 'double-walled carbon nanotube' www.cas.org/scifinder/scholar (Accessed 21 November 2009)

102 Cientifica: Nanotube Production Survey (summary) 2005

www.cientifica.eu/index.php?option $=$ com_co ntent \& task $=$ view $\&$ id $=37 \&$ Itemid $=74$ (Accessed 18 May 2007)

103 BCC Research: Carbon nanotubes: technologies and commercial prospects (highlights)

www.bccresearch.com/nan/NAN024C.asp (Accessed 18 May 2007)

104 Project on Emerging Nanotechnologies: A nanotechology consumer products inventory www.nanotechproject.org/index. php?id=44\&action = view (Accessed 18 May 2007)

105 Image J: Image processing and analysis in Java http://rsbweb.nih.gov/ij 